Pacific Journal of Mathematic 


\title{
ZERO SETS OF INTERPOLATING BLASCHKE PRODUCTS
}

\author{
KeIJI IZUCHI
}

\begin{abstract}
For a function $h$ in $H^{\infty}, Z(h)$ denotes the zero set of $h$ in the maximal ideal space of $H^{\infty}+C$. It is well known that if $q$ is an interpolating Blaschke product then $Z(q)$ is an interpolation set for $H^{\infty}$. The purpose of this paper is to study the converse of the above result. Our theorem is: If a function $h$ is in $H^{\infty}$ and $Z(h)$ is an interpolation set for $H^{\infty}$, then there is an interpolating Blaschke product $q$ such that $Z(q)=Z(h)$. As applications, we will study that for a given interpolating Blaschke product $q$, which closed subsets of $Z(q)$ are zero sets for some functions in $H^{\infty}$. We will also give a characterization of a pair of interpolating Blaschke products $q_{1}$ and $q_{2}$ such that $Z\left(q_{1}\right) \cup Z\left(q_{2}\right)$ is an interpolation set for $H^{\infty}$.
\end{abstract}

Let $H^{\infty}$ be the space of bounded analytic functions on the open unit disk $D$ in the complex number plane. Identifying a function $h$ in $H^{\infty}$ with its boundary function, $H^{\infty}$ becomes the (essentially) uniformly closed subalgebra of $L^{\infty}$, the space of bounded measurable functions on the unit circle $\partial D$. A uniformly closed subalgebra $B$ between $H^{\infty}$ and $L^{\infty}$ is called a Douglas algebra. We denote by $M(B)$ the maximal ideal space of $B$. Identifying a function $h$ in $B$ with its Gelfand transform, we regard $h$ as a continuous function on $M(B)$. Sarason [10] proved that $H^{\infty}+C$ is a Douglas algebra, where $C$ is the space of continuous functions on $\partial D$, and $M\left(H^{\infty}\right)=M\left(H^{\infty}+C\right) \cup D$. For a function $h$ in $H^{\infty}$, we denote by $Z(h)$ the zero set in $M\left(H^{\infty}+C\right)$ for $h$, that is,

$$
Z(h)=\left\{x \in M\left(H^{\infty}+C\right) ; h(x)=0\right\} .
$$

For a subset $E$ of $M\left(H^{\infty}\right)$, we denote by $\operatorname{cl}(E)$ the weak*-closure of $E$ in $M\left(H^{\infty}\right)$. A closed subset $E$ of $M\left(H^{\infty}\right)$ is called an interpolation set for $H^{\infty}$ if the restriction of $H^{\infty}$ on $E,\left.H^{\infty}\right|_{E}$, coincides with $C(E)$, the space of continuous functions on $E$. For points $x$ and $y$ in $M\left(H^{\infty}\right)$, we put

$$
\rho(x, y)=\sup \left\{|f(x)| ; f \in H^{\infty},\|f\| \leq 1, f(y)=0\right\} .
$$

We note that if $z$ and $w$ are points in $D, \rho(z, w)=|z-w| /|1-\bar{w} z|$, which is called the pseudo-hyperbolic distance on $D$. For a point $x$ in $M\left(H^{\infty}\right)$, we put

$$
P(x)=\left\{y \in M\left(H^{\infty}\right) ; \rho(x, y)<1\right\}
$$


which is called a Gleason part containing $x$. If $P(x)=\{x\}, P(x)$ is called trivial. For a distinct sequence $\left\{z_{n}\right\}_{n=1}^{\infty}$ in $D$ satisfying $\prod_{n=1}^{\infty}\left(1-\left|z_{n}\right|\right)<$ $\infty$,

$$
b(z)=\prod_{n=1}^{\infty}\left(\frac{-\bar{z}_{n}}{\left|z_{n}\right|} \frac{z-z_{n}}{1-\bar{z}_{n} n}\right)
$$

is called a Blaschke product with zeros $\left\{z_{n}\right\}_{n=1}^{\infty}$. A sequence $\left\{z_{n}\right\}_{n=1}^{\infty}$ in $D$ is called an interpolating sequence if for every bounded sequence $\left\{a_{n}\right\}_{n=1}^{\infty}$ there exists a function $h$ in $H^{\infty}$ such that $h\left(z_{n}\right)=a_{n}$ for every $n$. By Carleson's interpolation theorem [1], it is characterized by $\inf _{n} \Pi_{k: k \neq n} \rho\left(z_{n}, z_{k}\right)>0$. A Blaschke product is called interpolating if its zero sequence is interpolating.

It is well known that if $q$ is an interpolating Blaschke product, then $Z(q)$ is an interpolation set for $H^{\infty}$ (see [6, p. 205]). Our problem in this paper is to study the converse of the above assertion.

THEOREM 1. Let $h$ be a function in $H^{\infty}$ and let $h=\mathrm{IO}$ be an inner-outer factorization of $h$. If $Z(h)$ is an interpolation set for $H^{\infty}$, then

(i) $\mathrm{O}$ is invertible in $H^{\infty}$, and

(ii) there is an interpolating Blaschke product b such that $Z(b)=Z(h)$ and $\mathrm{I} \bar{b} \in H^{\infty}$.

We will give some applications of our theorem. The first question is; for a given interpolating Blaschke product, $q$, which closed subsets of $Z(q)$ are zero sets for some functions in $H^{\infty}$. We will give the complete answer in Corollary 1. In [8], we proved that a union set of two interpolation sets of $M\left(L^{\infty}\right)$ for $H^{\infty}$ is also an interpolation set, but there are two interpolating Blaschke products $q_{1}$ and $q_{2}$ such that $Z\left(q_{1}\right) \cup Z\left(q_{2}\right)$ is not an interpolation set. The second question is; for which pair of interpolating Blaschke products $q_{1}$ and $q_{2}, Z\left(q_{1}\right) \cup Z\left(q_{2}\right)$ is an interpolation set for $H^{\infty}$. The answer will be given in Corollary 4 .

To prove Theorem 1, we need some lemmas.

LEMMA 1 [6, p. 205]. If $b$ is an interpolating Blaschke product with zeros $\left\{z_{n}\right\}_{n=1}^{\infty}$, then $Z(b)=\operatorname{cl}\left(\left\{z_{n}\right\}_{n=1}^{\infty}\right) \backslash\left\{z_{n}\right\}_{n=1}^{\infty}$ and $Z(b)$ is an interpolation set for $H^{\infty}$.

The following lemma follows from Carleson's theorem [1].

LEMMA 2. Let $\left\{z_{n}\right\}_{n=1}^{\infty}$ and $\left\{w_{n}\right\}_{n=1}^{\infty}$ be disjoint interpolating sequences. Then $\left\{z_{n}, w_{n} ; n=1,2, \ldots\right\}$ is an interpolating sequence if and only if $\inf _{n, m} \rho\left(z_{n}, w_{m}\right)>0$. 
The following lemma follows from [7, Theorem 6.2].

LEMmA 3. Let $\left\{z_{n}\right\}_{n=1}^{\infty}$ and $\left\{w_{n}\right\}_{n=1}^{\infty}$ be sequences in $D$ and $\sigma$ be a positive constant with $0<\sigma<1$. If $\left|z_{n}\right| \rightarrow 1(n \rightarrow \infty)$ and $\rho\left(z_{n}, w_{n}\right)<\sigma$ for every $n$, then for each point $x$ in $\operatorname{cl}\left(\left\{w_{n}\right\}_{n=1}^{\infty}\right) \backslash\left\{w_{n}\right\}_{n=1}^{\infty}$, there is a point $y$ in $\operatorname{cl}\left(\left\{z_{n}\right\}_{n=1}^{\infty}\right) \backslash\left\{z_{n}\right\}_{n=1}^{\infty}$ such that $\rho(x, y) \leq \sigma$.

Proof of Theorem 1. Since $Z(h)$ is an interpolation set for $H^{\infty}$, by the open mapping theorem there is a constant $\sigma, 0<\sigma<1$, such that if $f \in C(Z(h))$ there is $f_{1} \in H^{\infty}$ with $f_{1}=f$ on $Z(h)$ and $\left\|f_{1}\right\|<\|f\| / \sigma$. Then we have

$$
\rho(x, y)>\sigma \text { for every } x, y \in Z(h), x \neq y .
$$

Consequently, there are no nontrivial Gleason part $P$ such that $Z(h) \supset P$. By the proof of [5, Corollary 1], $\mathrm{O}$ is invertible in $H^{\infty}$ and $\mathrm{I}$ is a finitely many product of interpolating Blaschke products $b_{l}, i=1,2, \ldots, n$. We note that the above proof depends deeply on Kerr-Lawson's lemmas in [9].

To prove (ii), it is sufficient to show the case $I=b_{1} b_{2}$ and $Z\left(b_{1}\right) \neq$ $Z(I)$. Let $\left\{z_{n}\right\}_{n=1}^{\infty}$ and $\left\{w_{n}\right\}_{n=1}^{\infty}$ be interpolating zero sequences of $b_{1}$ and $b_{2}$. Let $\left\{w_{1, n}\right\}_{n=1}^{\infty}$ be a subsequence of $\left\{w_{n}\right\}_{n=1}^{\infty}$ whose pseudo-hyperbolic distances from $\left\{z_{n}\right\}_{n=1}^{\infty}$ are less than $\sigma$, and put $\left\{w_{2, n}\right\}_{n=1}^{\infty}=$ $\left\{w_{n}\right\}_{n=1}^{\infty} \backslash\left\{w_{1, n}\right\}_{n=1}^{\infty}$. We denote by $q_{1}$ and $q_{2}$ the interpolating Blaschke products whose zero sequences are $\left\{w_{1, n}\right\}_{n=1}^{\infty}$ and $\left\{w_{2, n}\right\}_{n=1}^{\infty}$ respectively. By Lemma 2, $b_{1} q_{2}$ is an interpolating Blaschke product. By Lemma 1 and 3 , for each point $x$ in $Z\left(q_{1}\right)$, there is a point $y$ in $Z\left(b_{1}\right)$ such that $\rho(x, y) \leq \sigma$. Since $Z\left(q_{1}\right) \cup Z\left(b_{1}\right) \subset Z(h)$, by (1) we have $Z\left(q_{1}\right) \subset Z\left(b_{1}\right)$. Then we obtain

$$
Z(h)=Z(I)=Z\left(b_{1}\right) \cup Z\left(q_{1}\right) \cup Z\left(q_{2}\right)=Z\left(b_{1} q_{2}\right) .
$$

Thus $b=b_{1} q_{2}$ satisfies (ii).

Let $q$ be a non-continuous interpolating Blaschke product. By Theorem 1 , if $h \in H^{\infty}$ satisfies $Z(h) \subset Z(q)$, then there is an interpolating Blaschke product $b$ with $Z(b)=Z(h)$ and $h \bar{b} \in H^{\infty}$. It only shows that the zero sequence of $b$ can be found in the zero sequence of $h$. But the following corollary shows that there is an interpolating Blaschke product $b_{1}$ such that $Z\left(b_{1}\right)=Z(h)$ and $q \bar{b}_{1} \in H^{\infty}$. This fact means that the zero sequence of $b_{1}$ can be found in the zero sequence of $q$.

COROLlary 1. Let $q$ be an interpolating Blaschke product and let $E$ be a closed subset of $Z(q)$. Then the following assertions are equivalent.

(i) $E$ is an open-closed subset of $Z(q)$. 
(ii) There is an interpolating Blaschke product $b$ with $E=Z(b)$ and $q \bar{b} \in H^{\infty}$.

(iii) There is a function $h$ in $H^{\infty}$ with $E=Z(h)$.

Proof. Let $\left\{z_{n}\right\}_{n=1}^{\infty}$ be an interpolating zero sequence of $q$.

(i) $\Rightarrow$ (ii) Suppose that $E$ is an open-closed subset of $Z(q)$. Then there are disjoint open subsets $U$ and $V$ of $M\left(H^{\infty}\right)$ such that $U \supset E$ and $V \supset Z(q) \backslash E$. We may assume that $\left\{z_{n}\right\}_{n=1}^{\infty} \subset U \cup V$. Let $b$ be an interpolating Blaschke product with zeros $U \cap\left\{z_{n}\right\}_{n=1}^{\infty}$. Then $q \bar{b} \in H^{\infty}$. By Lemma 1 , we get $Z(b) \subset U \cap Z(q)=E$ and $Z(q \bar{b}) \subset V$. Thus we obtain

$$
E=E \cap Z(q)=E \cap(Z(b) \cup Z(q \bar{b}))=E \cap Z(b)=Z(b) .
$$

(ii) $\Rightarrow$ (iii) is trivial.

(iii) $\Rightarrow$ (i) By Lemma $1, Z(h)$ is an interpolation set for $H^{\infty}$. By Theorem 1, we may assume that $h$ is an interpolating Blaschke product and $Z(h) \subsetneq Z(q)$. We note that $Z(h) \neq Z(h q)=Z(q)$. By the proof of Theorem 1 (we put $b_{1}=h$ and $b_{2}=q$ ), there are interpolating Blaschke products $q_{1}$ and $q_{2}$ such that $q=q_{1} q_{2}, h q_{2}$ is an interpolating Blaschke product and $Z(h q)=Z\left(h q_{2}\right)$. Since $Z(h) \cap Z\left(q_{2}\right)=\varnothing$ and $Z(h) \cup\left(q_{2}\right)$ $=Z(h q)=Z(q), Z(h)$ is an open-closed subset of $Z(q)$.

COROLlARY 2. Let $q$ be an interpolating Blaschke product. Then there exists $h \in H^{\infty}$ such that $Z(q) \cap Z(h) \neq Z(g)$ for every $g \in H^{\infty}$.

Proof. By Corollary 1, it is sufficient to show the existence of $h$ in $H^{\infty}$ such that $Z(q) \cap Z(h)$ is not open in $Z(q)$. Let $\left\{z_{n}\right\}_{n=1}^{\infty}$ be the zero sequence of $q$. Let $\left\{E_{n}\right\}_{n=1}^{\infty}$ be a sequence of subsets of $\left\{z_{n}\right\}_{n=1}^{\infty}$ such that

$$
E_{n} \text { is an infinite subset, }
$$

$$
E_{n} \cap E_{m}=\varnothing \quad \text { if } n \neq m \text {, and }
$$

$$
\bigcup_{n=1}^{\infty} E_{n}=\left\{z_{n}\right\}_{n=1}^{\infty} \text {. }
$$

Then there exists a function $h$ in $H^{\infty}$ such that

$$
h=1 / n \text { on } E_{n} \text { for every } n=1,2, \ldots \text {. }
$$

We obtain $Z(q) \cap Z(h) \neq \varnothing$. By (2), there exists $x_{n} \in Z(q)$ such that $h\left(x_{n}\right)=1 / n$. Thus $Z(q) \cap Z(h)$ is not an open subset of $Z(q)$.

The following corollary shows that the assertion of Corollary 2 is also true if $Z(h)$ is replaced by $M(B)$ for some Douglas algebra $B$. 
COROLlary 3. Let $q$ be an interpolating Blaschke product. Then there is a Douglas algebra $B$ such that $Z(q) \cap M(B) \neq Z(g)$ for every $g \in H^{\infty}$.

Proof. For a subset $J$ of $L^{\infty}$, we denote by [ $\left.J\right]$ the uniformly closed subalgebra generated by $J$. By [8, Proposition 6.3], there exists a maximal Douglas algebra $B$ contained in $\left[H^{\infty}, \bar{q}\right]$ properly. Then we have $\bar{q} \notin B$. So we get $Z(q) \cap M(B) \neq \varnothing$. We shall show that $B$ satisfies our assertion. To show this, suppose not. By Corollary 1 , there exists an interpolating Blaschke product $b$ such that

$$
q \bar{b} \in H^{\infty} \quad \text { and } \quad Z(b)=Z(q) \cap M(B) .
$$

Then we have $\bar{b} \in\left[H^{\infty}, \bar{q}\right]$. By [3, Theorem 1], there is an interpolating Blaschke product $\psi$ such that

(6) $b \bar{\psi} \in H^{\infty}$ and $H^{\infty}+C \varsubsetneqq\left[H^{\infty}, \bar{\psi}\right] \varsubsetneqq\left[H^{\infty}, \bar{b}\right] \subset\left[H^{\infty}, \bar{q}\right]$.

This implies that there exists $x_{0}$ in $M\left(H^{\infty}+C\right)$ such that

$$
\left|\psi\left(x_{0}\right)\right|=1 \text { and } b\left(x_{0}\right)=0 \text {. }
$$

By (5), $q\left(x_{0}\right)=0$ and $x_{0} \notin M\left(\left[H^{\infty}, \bar{q}\right]\right)$. By (5) and (7), we have $x_{0} \in$ $M(B)$ and $x_{0} \in M([B, \bar{\psi}])$, consequently $\left[H^{\infty}, \bar{q}\right] \neq[B, \bar{\psi}]$. By $(6)$, we get $\bar{\psi} \in\left[H^{\infty}, \bar{q}\right]$. Since $B$ is maximal in $\left[H^{\infty}, \bar{q}\right]$, we get $\bar{\psi} \in B$. But by (5) and (6), we have

$$
\varnothing \neq Z(\psi) \subset Z(b) \subset M(B),
$$

so we obtain $\bar{\psi} \notin B$. This is a contradiction.

Corollary 4. Let $q_{1}$ and $q_{2}$ be interpolating Blaschke products. Then the following conditions are equivalent.

(i) $Z\left(q_{1}\right) \cup Z\left(q_{2}\right)$ is an interpolation set for $H^{\infty}$.

(ii) $Z\left(q_{1}\right) \cap Z\left(q_{2}\right)$ is an open-closed subset of $Z\left(q_{1}\right)$.

(iii) There exists an interpolating Blaschke product $q_{3}$ such that $Z\left(q_{3}\right)=$ $Z\left(q_{1}\right) \cap Z\left(q_{2}\right)$.

Proof. (i) $\Rightarrow$ (ii) We put $q=q_{1} q_{2}$. By (i), $Z(q)=Z\left(q_{1}\right) \cup Z\left(q_{2}\right)$ is an interpolation set for $H^{\infty}$. By Theorem 1 , we may assume that $q$ is an interpolating Blaschke product. By Corollary $1, Z\left(q_{2}\right)$ is an open-closed subset of $Z\left(q_{1}\right) \cup Z\left(q_{2}\right)$. Then $Z\left(q_{1}\right) \cap Z\left(q_{2}\right)$ is an open-closed subset of $Z\left(q_{1}\right)$.

(ii) $\Rightarrow$ (iii) follows from Corollary 1 .

(iii) $\Rightarrow$ (i) By Corollary 1, (iii) implies that $Z\left(q_{1}\right) \cap Z\left(q_{2}\right)$ and $Z\left(q_{1}\right) \backslash Z\left(q_{2}\right)$ are open-closed subsets of $Z\left(q_{1}\right)$, and $Z\left(q_{2}\right) \backslash Z\left(q_{1}\right)$ is an open-closed subset of $Z\left(q_{2}\right)$. Again by Corollary 1 , there are interpolating 
Blaschke products $b_{1}, b_{2}$ and $b_{3}$ such that $Z\left(b_{1}\right)=Z\left(q_{1}\right) \cap Z\left(q_{2}\right), Z\left(b_{2}\right)$ $=Z\left(q_{1}\right) \backslash Z\left(q_{2}\right)$ and $Z\left(b_{3}\right)=Z\left(q_{2}\right) \backslash Z\left(q_{1}\right)$. By Lemmas 1,2 and 3 , we may assume that $b_{1} b_{2} b_{3}$ is an interpolating Blaschke product. Consequently, $Z\left(q_{1}\right) \cup Z\left(q_{2}\right)=Z\left(b_{1} b_{2} b_{3}\right)$ is an interpolation set for $H^{\infty}$.

The author would like to thank the referee and Y. Izuchi for shortening the proof of Theorem 1.

\section{REFERENCES}

[1] L. Carleson, An interpolation problem for bounded analytic functions, Amer. J. Math., 80 (1958), 921-930.

[2] K. Clancey and W. Cutrer, Subalgebras of Douglas algebras, Proc. Amer. Math. Soc., 40 (1973), 102-106.

[3] T. Gamelin, Uniform Algebras, Prentice Hall, New Jersey, 1969.

[4] J. Garnett, Bounded Analytic Functions, Academic Press, New York, 1981.

[5] C. Guillory, K. Izuchi and D. Sarason, Interpolating Blaschke products and division in Douglas algebras, Proc. Royal Irish Acad., 84A (1984), 1-7.

[6] K. Hoffman, Banach Spaces of Analytic Functions, Prentice Hall, New Jersey, 1962.

[7] _ Bounded analytic functions and Gleason parts, Ann. of Math., 86 (1967), 74-111.

[8] K. Izuchi and Y. Izuchi, Annihilating measures for Douglas algebras, Yokohama Math. J., 32 (1984), 135-151.

[9] A. Kerr-Lawson, Some lemmas on interpolating Blaschke products and a correction, Canad. J. Math., 21 (1969), 531-534.

[10] D. Sarason, Function Theory on the Unit Circle, Virginia Poly. Inst. and State Univ., Blacksburg, Virginia, 1978.

Received May 20, 1983 and in revised form July 20, 1984.

Kanagawa UNIVERSITY

YOKOHAMa 221, JAPAN 


\section{PACIFIC JOURNAL OF MATHEMATICS EDITORS}

\author{
V. S. VARADARAJAN (Managing Editor) \\ University of California \\ Los Angeles, CA 90024 \\ Charles R. DePrima \\ California Institute of Technology \\ Pasadena, CA 91125 \\ R. FInN \\ Stanford University \\ Stanford, CA 94305
}

\section{HeRmanN FlaschKa \\ University of Arizona \\ Tucson, AZ 85721}

Ramesh A. Gangolli

University of Washington

Seattle, WA 98195

ROBION KIRBY

University of California

Berkeley, CA 94720

\section{C. MOORE}

University of California

Berkeley, CA 94720

\section{H. SAMELSON}

Stanford University

Stanford, CA 94305

HAROLD STARK

University of California, San Diego

La Jolla, CA 92093

\section{ASSOCIATE EDITORS}
R. ARENS
E. F. BECKENBACH
B. H. NeumanN
F. Wolf
K. Yoshida (1906-1982)

\section{SUPPORTING INSTITUTIONS}
CALIFORNIA INSTITUTE OF TECHNOLOGY

\author{
UNIVERSITY OF SOUTHERN CALIFORNIA \\ STANFORD UNIVERSITY \\ UNIVERSITY OF HAWAII \\ UNIVERSITY OF TOKYO \\ UNIVERSITY OF UTAH \\ WASHINGTON STATE UNIVERSITY \\ UNIVERSITY OF WASHINGTON
}
UNIVERSITY OF OREGON

\begin{abstract}
UNIVERSITY OF ARIZONA
UNIVERSITY OF BRITISH COLUMBIA

UNIVERSITY OF CALIFORNIA

MONTANA STATE UNIVERSITY

UNIVERSITY OF NEVADA, RENO

NEW MEXICO STATE UNIVERSITY

OREGON STATE UNIVERSITY
\end{abstract}

The Supporting Institutions listed above contribute to the cost of publication of this Journal, but they are not owners or publishers and have no responsibility for its content or policies.

Mathematical papers intended for publication in the Pacific Journal of Mathematics should be in typed form or offset-reproduced (not dittoed), double spaced with large margins. Please do not use built up fractions in the text of the manuscript. However, you may use them in the displayed equations. Underline Greek letters in red, German in green, and script in blue. The first paragraph must be capable of being used separately as a synopsis of the entire paper. In particular it should contain no bibliographic references. Please propose a heading for the odd numbered pages of less than 35 characters. Manuscripts, in triplicate, may be sent to any one of the editors. Please classify according to the scheme of Math. Reviews, Index to Vol. 39. Supply name and address of author to whom proofs should be sent. All other communications should be addressed to the managing editor, or Elaine Barth, University of California, Los Angeles, California 90024.

There are page-charges associated with articles appearing in the Pacific Journal of Mathematics. These charges are expected to be paid by the author's University, Government Agency or Company. If the author or authors do not have access to such Institutional support these charges are waived. Single authors will receive 50 free reprints; joint authors will receive a total of 100 free reprints. Additional copies may be obtained at cost in multiples of 50 .

The Pacific Journal of Mathematics is issued monthly as of January 1966. Regular subscription rate: $\$ 190.00$ a year (5 Vols., 10 issues). Special rate: $\$ 66.00$ a year to individual members of supporting institutions.

Subscriptions, orders for numbers issued in the last three calendar years, and changes of address should be sent to Pacific Journal of Mathematics, P.O. Box 969, Carmel Valley, CA 93924, U.S.A. Old back numbers obtainable from Kraus Periodicals Co., Route 100, Millwood, NY 10546.

The Pacific Journal of Mathematics at P.O. Box 969, Carmel Valley, CA 93924 (ISSN 0030-8730) publishes 5 volumes per year. Application to mail at Second-class postage rates is pending at Carmel Valley, California, and additional mailing offices. Postmaster: Send address changes to Pacific Journal of Mathematics, P.O. Box 969, Carmel Valley, CA 93924.

PUBLISHED BY PACIFIC JOURNAL OF MATHEMATICS, A NON-PROFIT CORPORATION

Copyright $\odot 1985$ by Pacific Journal of Mathematics 


\section{Pacific Journal of Mathematics}

Vol. 119, No. $2 \quad$ June, 1985

Mustafa Agah Akcoglu and Meira Falkowitz (Soshniak), A general local

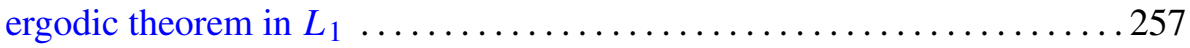

W. Wistar (William) Comfort and Lewis Chandlee Robertson,

Cardinality constraints for pseudocompact and for totally dense

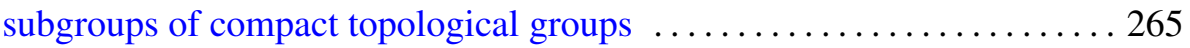

John Morse Delaurentis and Boris G. Pittel, Random permutations and

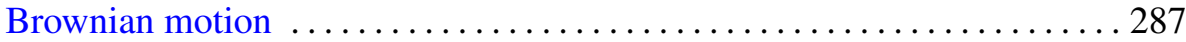

José Esteban Galé, Gel'fand theory in algebras of differentiable functions on Banach spaces ......................................... 303

Harry Gingold, On the location of zeroes of oscillatory solutions of

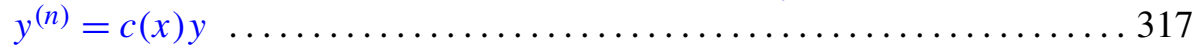

Kei Ji Izuchi, Zero sets of interpolating Blaschke products .............337

Mahesh Nerurkar, Ergodic continuous skew product actions of amenable

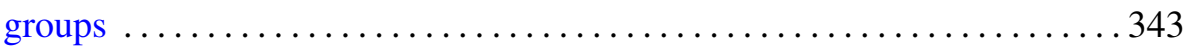

R. Owens, A maximal function characterization of a class of Hardy

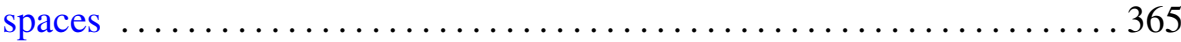

Judith Anne Packer, Point spectrum of ergodic abelian group actions and the corresponding group-measure factors $\ldots \ldots \ldots \ldots \ldots \ldots \ldots \ldots \ldots \ldots \ldots \ldots$

Judith Anne Packer, On the embedding of subalgebras corresponding to quotient actions in group-measure factors $\ldots \ldots \ldots \ldots \ldots \ldots \ldots \ldots . \ldots 4$

Iain Raeburn and Joseph L. Taylor, The bigger Brauer group and étale cohomology

David Rosen, The Diophantine equation $a x+b y=c$ in $Q(\sqrt{5})$ and other number fields

Mau-Hsiang Shih and Kok Keong Tan, Noncompact sets with convex sections

Lee Barlow Whitt, Codimension two isometric immersions between Euclidean spaces

Rodney Ian Yager, Iwasawa theory for the anticyclotomic extension 